\title{
Improved isolation and detection of toxigenic Vibrio parahaemolyticus from coastal water in Saudi Arabia using immunomagnetic enrichment
}

\author{
Mariam Almejhim ${ }^{1}$, Mohammed Aljeldah ${ }^{2}$, Nasreldin Elhadi ${ }^{\text {Corresp. } 1}$ \\ ${ }^{1}$ Department of Clinical Laboratory Science, College of Applied Medical Sciences, Imam Abdulrahman Bin Faisal University, Dammam, Saudi Arabia \\ 2 Department of Clinical Laboratory Science, College of Applied Medical Sciences, University of Hafr Al-Batin, Hafr Al-Batin, Saudi Arabia \\ Corresponding Author: Nasreldin Elhadi \\ Email address: nmohammed@iau.edu.sa
}

Background. Vibrio parahaemolyticus is recognized globally as a cause of foodborne gastroenteritis and its widely disseminated in marine and coastal environment throughout the world. The main aim of this study was conducted to investigate the presence of toxigenic V. parahaemolyticus in costal water in the Eastern Province of Saudi Arabia by using immunomagnetic separation (IMS) in combination with chromogenic Vibrio agar medium and PCR targeting toxR gene of species level and virulence genes. Methods. A total of 192 seawater samples were collected from 5 locations and enriched in alkaline peptone water (APW) broth. One-millimeter portion from enriched samples in APW were mixed with an immunomagnetic beads (IMB) coated with specific antibodies against $V$. parahaemolyticus polyvalent $\mathrm{K}$ antisera and separated beads with captured bacteria streaked on thiosulfate citrate bile salts sucrose (TCBS) agar and CHROMagar Vibrio (CaV) medium. Results. Of the 192 examined seawater samples, 38 (19.8\%) and 44 (22.9\%) were positive for $V$. parahaemolyticus, producing green and mauve colonies on TCBS agar and $\mathrm{CaV}$ medium, respectively. Among 120 isolates of $\mathrm{V}$. parahaemolyticus isolated in this study, $3(2.5 \%)$ and $26(21.7 \%)$ isolates of $V$. parahaemolyticus isolated without and with IMB treatment tested positive for the toxin regulatory (toxR) gene, respectively. Screening of the confirmed toxR gene-positive isolates revealed that 21 (17.5\%) and $3(2.5 \%)$ were positive for the thermostable direct hemolysin $(t d h)$ encoding gene in strains isolated with IMB and without IMB treatment, respectively. None of the $V$. parahaemolyticus strains tested positive for the thermostable related hemolysin (trh) gene. In this study, we found that the CaV medium has no advantage over TCBS agar if IMB concentration treatment is used during secondary enrichment steps of environmental samples. The enterobacterial repetitive intergenic consensus (ERIC)-PCR DNA fingerprinting analysis revealed high genomic diversity, and 18 strains of $V$. parahaemolyticus were grouped and identified into four identical ERIC clonal group patterns. Conclusions. The presented study reports the 
first detection of $t d h$ producing $V$. parahaemolyticus in coastal water in the Eastern Province of Saudi Arabia. 


\section{Improved isolation and detection of toxigenic Vibrio}

2 parahaemolyticus from coastal water in Saudi Arabia

\section{3 using immunomagnetic enrichment}

4

5 Mariam Almejhim ${ }^{1}$, and Mohammed Aljeldah ${ }^{2}$ and Nasreldin Elhadi ${ }^{1, *}$

6

Corresponding Author:

Nasreldin Elhadi

Department of Clinical Laboratory Science, College of Applied Medical Sciences, Imam Abdulrahman Bin Faisal University, P.O. Box 2435, 31441 Dammam, Kingdom of Saudi Arabia

Email address: nmohammed@iau.edu.sa

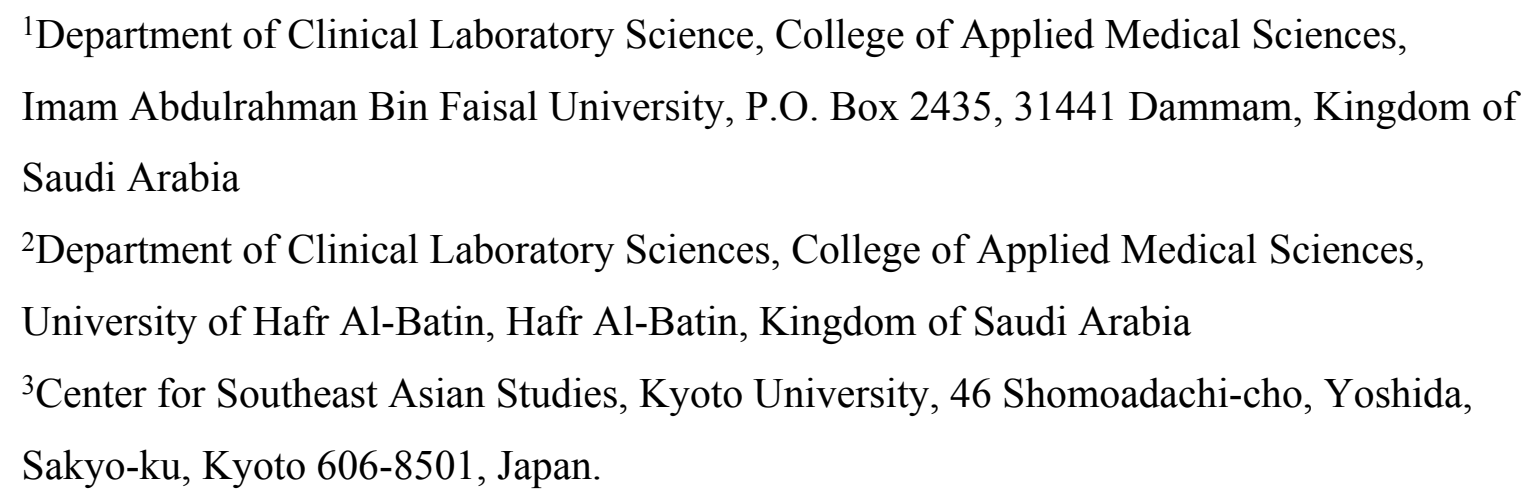




\section{Abstract}

23 Background. Vibrio parahaemolyticus is recognized globally as a cause of foodborne

24 gastroenteritis and its widely disseminated in marine and coastal environment throughout the

25

26

27

28

29

30

31

32 world. The main aim of this study was conducted to investigate the presence of toxigenic $V$. parahaemolyticus in costal water in the Eastern Province of Saudi Arabia by using immunomagnetic separation (IMS) in combination with chromogenic Vibrio agar medium and PCR targeting tox $R$ gene of species level and virulence genes.

Methods. A total of 192 seawater samples were collected from 5 locations and enriched in alkaline peptone water (APW) broth. One-millimeter portion from enriched samples in APW were mixed with an immunomagnetic beads (IMB) coated with specific antibodies against $V$. parahaemolyticus polyvalent $\mathrm{K}$ antisera and separated beads with captured bacteria streaked on thiosulfate citrate bile salts sucrose (TCBS) agar and CHROMagar Vibrio $(\mathrm{CaV})$ medium. Results. Of the 192 examined seawater samples, 38 (19.8\%) and 44 (22.9\%) were positive for $V$. parahaemolyticus, producing green and mauve colonies on TCBS agar and CaV medium, respectively. Among 120 isolates of $V$. parahaemolyticus isolated in this study, 3 (2.5\%) and 26 $(21.7 \%)$ isolates of $V$. parahaemolyticus isolated without and with IMB treatment tested positive for the toxin regulatory (toxR) gene, respectively. Screening of the confirmed tox Renepositive isolates revealed that $21(17.5 \%)$ and $3(2.5 \%)$ were positive for the thermostable direct hemolysin $(t d h)$ encoding gene in strains isolated with IMB and without IMB treatment, respectively. None of the $V$. parahaemolyticus strains tested positive for the thermostable related hemolysin (trh) gene. In this study, we found that the CaV medium has no advantage over TCBS agar if IMB concentration treatment is used during secondary enrichment steps of environmental samples. The enterobacterial repetitive intergenic consensus (ERIC)-PCR DNA fingerprinting analysis revealed high genomic diversity, and 18 strains of $V$. parahaemolyticus were grouped and identified into four identical ERIC clonal group patterns.

Conclusions. The presented study reports the first detection of $t d h$ producing $V$. parahaemolyticus in coastal water in the Eastern Province of Saudi Arabia.

Keywords: coastal environment; immunomagnetic beads; PCR; Vibrio parahaemolyticus 


\section{Introduction}

54 Vibrio parahaemolyticus is a halophilic bacterium that is abundant in marine and estuarine

55 environments (Kalburge et al., 2014). The highest abundance of $V$. parahaemolyticus is in

56 sediment and benthic environments (Böer et al., 2013). V. parahaemolyticus is also present in

57 various types of marine seafood and organisms, such as shrimps, mollusks, oysters, fish, crabs,

58 lobsters, mussels, and zooplankton (DePaola et al., 2003; Su and Liu, 2007; Julie et al., 2010;

59 Letchumanan et al., 2014). However, the growth of $V$. parahaemolyticus has an absolute salt

60 requirement for survival and is capable of growth at 1 to $9 \% \mathrm{NaCl}$ (Whitaker et al., 2010;

61 Kalburge et al., 2014). The presence of $V$. parahaemolyticus in the environment widely varies

62 according to differences in geographical locations and environmental factors, such as

63 temperature and salinity (Parveen et al., 2008; Johnson et al., 2012). V. parahaemolyticus is

64 reported to grow at temperatures ranges from $5^{\circ} \mathrm{C}$ to $43^{\circ} \mathrm{C}(I C M S F, 1996)$ and the salinity ranges

65 between 1 to 35 parts per thousand (ppt) (FAO and WHO, 2020). Several studies have reported

66 an association between the isolation of $V$. parahaemolyticus and a higher temperature of

67 seawaters (Blackwell and Oliver, 2008). In the Chesapeake Bay, USA, the detection of $V$.

68 parahaemolyticus was rare and difficult until the temperature reached $19^{\circ} \mathrm{C}$ or above (Kaneko

69 and Colwell, 1973). Also, during the winter season, V. parahaemolyticus will survive in the

70 sediment; it usually appears in the water column at the end of spring or the beginning of the

71 summer season (Julie et al., 2010). On the other hand, the salinity of the seawater affects the

72 presence or absence of $V$. parahaemolyticus in the environment (Johnson et al., 2010).

73 The most pathogenic virulence factors of $V$. parahaemolyticus are thermostable direct

74 hemolysin (TDH), and TDH-related hemolysin (TRH) (Tada et al., 1992), but the underlying

75 mechanism of these proteins in human infection remains unknown (Broberg et al., 2011;

76 Ceccarelli et al., 2013). V. parahaemolyticus can cause wide-scale infection transmitted through

77 the consumption of raw or undercooked contaminated seafood, usually during the warmer 
78 months (Baker-Austin et al., 2017). The infection takes between 4 to $24 \mathrm{~h}$; then, the symptoms 79 begin to appear and self-resolve within 48 to $72 \mathrm{~h}$. However, three significant medical conditions 80 can be caused by $V$. parahaemolyticus: acute gastroenteritis, wound infection, and septicemia 81 (Nair et al., 2007). Acute gastroenteritis appears with abdominal pain, diarrhea, vomiting, 82 nausea, and headache with fever, as well as sometimes with bloody diarrhea (Li et al., 2016).

83 Wound infection is commonly detected in fishermen with a small wound occurring at the time of 84 fishing in contaminated seawater; usually, the infected person will suffer from cellulitis, though 85 in some cases, the infection will progress to severe necrotizing fasciitis (Hlady and Klontz, 86 1996). Very few cases of $V$. parahaemolyticus lead to septicemia, which might be fatal to a 87 person with an underlying medical problem, including immunocompromised patients, such as 88 those with cancer or liver diseases (Jia et al., 2016).

$V$. parahaemolyticus is commonly isolated from Asian regions because of the nature of the food consumed in these countries. Therefore, outbreaks start in various countries in Asia, such as Japan, India, and China (Hara-Kudo et al., 2001; Yonekita et al., 2020). The main cause of outbreaks in Asian regions has been reported as the consumption of contaminated seafood (Jacxsens et al., 2009; Yonekita et al., 2020). Globally and compared with other foodborne illnesses, $V$. parahaemolyticus infections have been increasing and have become the leading cause of seafood bacterial infections (Martinez-Urtaza et al., 2010; Abanto et al., 2020). In Saudi Arabia, no report of isolation of $V$. parahaemolyticus from any clinical cases and most of the reported isolation from environmental samples (Elhadi, 2013; Elhadi \& Nishibuchi, 2018; Ghenem \& Elhadi, 2018).

The US Centers for Disease Control and Prevention (CDC) estimated that the average annual incidence of all Vibrio infections increased by 54\% during 2006-2017 (Marder Mph et al., 2018), and V.parahaemolyticus was responsible for the highest number of infections (Newton et al., 2014). In the United States, V.parahaemolyticus is responsible for more than 35,000 human infections per year, and in China, since 1990, V. parahaemolyticus has been registered as the leading cause of foodborne infections (Scallan et al., 2011; Liu et al., 2011). In the summer of 2004, in Alaska, 14 passengers were infected on a cruise trip after consuming raw oysters (McLaughlin et al., 2005). The largest outbreak of $V$. parahaemolyticus was in the summer of 2012 on a cruise boat in Spain; 100 out of 114 passengers were infected. After a laboratory investigated, they found different genes and reported the first presence of $V$. 
109 parahaemolyticus strains carrying both the $t d h+$ and $t r h+$ pathogenicity genes (Martinez-Urtaza 110 et al., 2016).

111 Not all $V$. parahaemolyticus strains are pathogenic, only those expressing $t d h$ that encodes

112 the tdh or trh genes (Tada et al., 1992; Ceccarelli et al., 2013; Saito et al., 2015). Therefore, the 113 objectives of the present study were (i) to isolate $V$. parahaemolyticus from coastal water by 114 using IMBs in samples treatment to concentrate bacteria after the enrichment process; (ii) to 115 confirm all isolates of $V$. parahaemolyticus to species level by using PCR targeted to the tox $\mathrm{R}$ 116 gene; (iii) to examine all toxR gene-positive isolates for the presence of the $t d h$ and $t r h$ genes 117 using PCR; and (iv) to genotype all isolates of $V$. parahaemolyticus tox $\mathrm{R}$ gene-positive isolated 118 from different locations along the coast of Eastern Province of Saudi Arabia for relative genetic 119 similarity by using enterobacterial repetitive intergenic consensus (ERIC)-PCR.

120

121

\section{MATERIALS AND METHODS}

122

\section{Study design and sample collection}

124 In the present study, a total of 192 sea surface water samples were collected from five different 125 sites along the coast of the Eastern Province of Saudi Arabia between March 2018 and May 126 2018. All samples were collected in sterile $500 \mathrm{ml} \mathrm{screw-cap} \mathrm{bottles} \mathrm{from:} \mathrm{(i)} 40$ samples from 127 Al aziziyah beach (AZB); (ii) 39 samples from corniche Al-Khobar (KBC); (iii) 38 samples from corniche Al-Khobar front (KBF); (iv) 36 samples from Dammam beach (DMB); and 39 samples from Half-Moon beach (HMF) as illustrated in Fig. 1. During sample collection from each location, the temperature and $\mathrm{pH}$ of surface seawater were measured using a Multi-Parameter Water Quality Meter (YSI-50 series, Horiba, USA). Seawater samples were transported after collection to the microbiology research laboratory at Imam Abdurrahman bin Faisal University (IAU) and processed immediately to test for the presence of $V$. parahaemolyticus. Seawater samples were analyzed in accordance with the FDA method for Vibrio isolation (DePaola and Kaysner, 2004). All water samples were enriched in alkaline peptone water (APW). The preparation of $1 \%$ and $3 \%$ APW was performed as described in the Bacteriological Analytical Manual (DePaola and Kaysner, 2004). 
139 Enrichment process

140 All samples were treated by adding $25 \mathrm{ml}$ of the seawater sample into $225 \mathrm{ml}$ enrichment 141 medium of alkaline peptone water broth (APW) supplemented with $3 \% \mathrm{NaCl}$ and incubated

142 at $37^{\circ} \mathrm{C}$ for $24 \mathrm{~h}$. On the second day, a loop full of each enriched sample was streaked on

143 Thiosulfate citrate bile salts sucrose (TCBS) agar (Oxoid, UK) and CHROM agar (CHROM, 144 France) and incubated at $37^{\circ} \mathrm{C}$ for $24 \mathrm{~h}$.

\section{Immunomagnetic beads (IMB) separation of $\boldsymbol{V}$. parahaemolyticus}

146 The concentration of suspected V. parahaemolyticus in enriched samples in APW were done 147 using commercially available magnetic beads coated with antibodies against $V$. 148 parahaemolyticus polyvalent K antisera groups I to IX (Denka Seiken, Tokyo, Japan). The 149 magnetic bead was prepared as previously described with modifications (Tanaka et al., 2014). 150 Briefly, $1 \mathrm{ml}$ from each enriched sample in APW supplemented with $3 \% \mathrm{NaCl}$ was inoculated 151 into tryptic soy broth (TSB) with $2 \% \mathrm{NaCl}$ for second enrichment and incubated at $37^{\circ} \mathrm{C}$ for $24 \mathrm{~h}$.

152 Then, $1 \mathrm{ml}$ was transferred from the second enrichment samples into $1.5 \mathrm{ml}$ tube and mixed with $15320 \mu \mathrm{l}$ of IMB specific to $V$. parahaemolyticus. All mixed tubes with IMB were gently inverted 154 and incubated for $45 \mathrm{~min}$ at room temperature. The magnetic concentrator rack was used to 155 separate the beads with captured bacteria from enriched samples and washed three times with 156 phosphate buffer saline (PBS). Finally, the bead-aggregated bacterium were resuspended in $50 \mu 1$ 157 of PBS and spread on TCBS and CaV agar and incubated at $37^{\circ} \mathrm{C}$ for $24 \mathrm{~h}$. At least 3 to 5 typical 158 colonies of suspected V. parahaemolyticus "sucrose non-fermenting" (green or blue) on TCBS 159 agar and "mauve" colonies on $\mathrm{CaV}$ agar were selected from each selective media and sub160 cultured on tryptic soya agar (TSA) supplemented with $2 \%$. Then, they were incubated at $37^{\circ} \mathrm{C}$

161 162 163 164 165 166 167 168 overnight for subsequent PCR confirmation. Finally, the results of isolated $V$. parahaemolyticus with and without IMB treatment could be compared.

\section{DNA template preparation}

DNA extraction was done for all selected colonies on TCBS and $\mathrm{CaV}$ agar isolated with and without IMB as described elsewhere (Elhadi et al., 2018). Briefly, $1 \mathrm{ml}$ of an overnight test culture in Luria Bertani (LB) broth was transferred into a $1.5 \mathrm{ml}$ tube and centrifuged at 10,000 rpm for $2 \mathrm{~min}$, and the supernatant was discarded. The obtained pellet was suspended in sterilized distilled water and boiled at $100^{\circ} \mathrm{C}$ for $15 \mathrm{~min}$. Then the tube was centrifuged at 12,000 
$169 \mathrm{rpm}$ for $5 \mathrm{~min}$, and the supernatant was transferred to a new tube and stored at $-20^{\circ} \mathrm{C}$ until use.

170 Identification of $\boldsymbol{V}$. parahaemolyticus to species level using PCR

171 targeted to the toxR gene

172 The confirmation of $V$. parahaemolyticus to species level was performed using PCR targeted to

173 the toxR gene, as described previously (Kim et al., 1999). All isolates of $V$. parahaemolyticus

174 isolated with and without IMB were screened for tox $\mathrm{R}$ gene amplicon (size $368 \mathrm{bp}$ ) using primer

175 sequence, as indicated in Table 1. Positive and negative DNA controls of $V$. parahaemolyticus

176 strains (ATCC 17802) and V. alginolyticus (ATCC 17749) were included in all PCR assays.

177 A positive $V$. parahaemolyticus (ATCC 17802) and negative of $V$. alginolyticus (ATCC 17749)

178 control were included in each PCR run.

\section{Detection of virulence gene markers}

180 All toxR-positive isolates of $V$. parahaemolyticus recovered on TCBS and CaV agar with and

181

182

183

184

185

186

187

188

189

190

191

192

193

194

195

196

197

without IMB were tested for the presence or absence of tdh and trh virulence gene markers following a previously described protocol (Tada et al., 1992). Briefly, the total volume of the reaction was $25 \mu \mathrm{l}$, consisting of $12.5 \mu \mathrm{l}$ of GoTaq Green Master Mix (Promega, USA), $2 \mu \mathrm{l}$ of DNA template, $8.5 \mu$ nuclease-free water (Promega, USA), and $2 \mu$ of forward and reverse primers (Invitrogen, Japan) (Table 1). The positive controls of $V$. parahaemolyticus strains ATCC 17802, V. parahaemolyticus AQ3815, and V. parahaemolyticus AQ4037 were used in each PCR control for the toxR, $t d h$, and $t r h$ genes, respectively. Amplification of both the 251 and $250 \mathrm{bp}$ region for the $t d h$ and $t r h$ genes were performed following the described conditions by Tada et al. (1992): 35 cycles of denaturation at $94^{\circ} \mathrm{C}$ for $1 \mathrm{~min}$, annealing at $59^{\circ} \mathrm{C}$ for $1 \mathrm{~min}$, and extension at $72^{\circ} \mathrm{C}$ for $1 \mathrm{~min}$, followed by a final extension at $72^{\circ} \mathrm{C}$ for $7 \mathrm{~min}$. Finally, $10 \mu \mathrm{l}$ of amplified products were separated using electrophoresis in 1.5\% agarose gels stained with ethidium bromide in 1X Tris borate EDTA buffer (Promega, USA).

\section{Molecular typing analysis}

In order to study genotypes, $V$. parahaemolyticus tox R positive isolates were fingerprinted using enterobacterial repetitive intergenic consensus (ERIC)-PCR as described elsewhere. Briefly, ERIC-PCR was performed using two repetitive primer set sequences, ERIC1R (5'- 
198 3'), as described previously (Versalovic et al., 1991). ERIC-PCR was performed in a volume of $19925 \mu \mathrm{l}$ containing $12.5 \mu \mathrm{l}$ of GoTaq Green Master Mix (Promega, USA), $3 \mu \mathrm{l}$ of DNA template, 2 $200 \mu \mathrm{l}$ of ERIC primer, and $7.5 \mu \mathrm{l}$ nuclease-free water. The PCR reactions were performed using a 201 Bio-Rad T100 thermocycler (Bio-Rad, USA) as follows: 4 min at $94^{\circ} \mathrm{C}$, followed by 35 cycles of $20294^{\circ} \mathrm{C}$ for $1 \mathrm{~min}, 52^{\circ} \mathrm{C}$ for $1 \mathrm{~min}$ and $65^{\circ} \mathrm{C}$ for $1 \mathrm{~min}$, with a final extension at $65^{\circ} \mathrm{C}$ for $10 \mathrm{~min}$. The 203 ERC-PCR fingerprint patterns obtained by electrophoresis were analyzed by GelJ software 204 (Heras et al., 2015). The dendrogram was constructed with the unweighted average pair group 205 method (UPGMA) with a band position tolerance of $1 \%$.

206

207

Results

208

209

210

211

\section{Physical parameters of water}

Seawater temperature values ranged from $25^{\circ} \mathrm{C}$ to $31^{\circ} \mathrm{C}$ during the sampling events from 212 February to May 2018 (Table 2). The highest water temperature was documented during April 2132018 at Half-Moon beach (HMF), while the lowest value was logged in February at Alaziziyah 214 beach (AZB). The water $\mathrm{pH}$ values ranged from 7.35 to 8.46 . The highest $\mathrm{pH}$ was recorded 215 during April 2018 in Dammam corniche (DMC), while the lowest was recorded during March 2162018 in Alkhubar corniche (KBC) (Table 2). The highest number of positive samples for $V$.

217 parahemolyticus was recorded in Half-Moon beach, and the seawater $\mathrm{pH}$ and temperature values 218 were 8.22 and $31^{\circ} \mathrm{CM}$, respectively (Table 2 ).

\section{Immunomagnetic bead (IMB) separation of $V$. parahaemolyticus}

In this study, samples were considered positive for V. parahaemolyticus based on the preliminary 223 appearance of green and mauve colonies on TCBS and CaV agar isolated with IMB and without IMB enrichment treatment (File S1). Among the examined samples, the highest number of positive samples for $V$. parahaemolyticus was detected in samples enriched with IMB and the lowest in samples enriched without IMB (Table 2). The highest distribution rate of positive samples for $V$. parahaemolyticus isolated with IMB on $\mathrm{CaV}$ medium was found at HMF 19 (48.7\%) and AZB beach 15 (37.5\%) as shown in Table 2. Whereas the highest positive samples rates for $V$. parahaemolyticus isolated with IMB on TCBS agar was 17 (43.7\%) and 11 (27.5\%) 
231 that were enriched in alkaline peptone water broth and processed without using IMB in 232 secondary enrichment, only $3(1.6 \%)$ and $5(2.6 \%)$ samples were reported positive for $V$. 233 parahaemolyticus on TCBS agar and CHROMagar Vibrio, respectively (Table 2). After 234 enrichment with IMB, the rate number of positive samples was $38(19.8 \%)$ and $44(22.9 \%)$ for $V$. 235 parahaemolyticus on TCBS and $\mathrm{CaV}$ agar from all locations, respectively (Table 2). A total of 23648 and 58 isolates of $V$. parahaemolyticus were isolated on TCBS and CaV agar with IMB, 237 respectively (Table 2). Among the five locations, the highest number of $V$. parahaemolyticus 238 isolates were isolated from HMF (Table 2). The abundance of $V$. parahaemolyticus isolates were 239 recovered on TCBS and $\mathrm{CaV}$ agar from samples examined from all locations after using IMB in the secondary enrichment process (Table 2). In this, we found that the use of IMB in secondary enrichment of examined seawater samples could successfully recover typical colonies of $V$.

parahaemolyticus on $\mathrm{CaV}$ and TCBS agar, outperforming when samples were plated on $\mathrm{CaV}$ and

243 TCBS agar without the use of IMB in secondary enrichment.

244

245

246

247

248

249

\section{Confirmation of $V$. parahaemolyticus to species level using PCR targeted to the toxR gene}

To confirm the identification of $V$. parahaemolyticus more accurately to species level and for comparison purposes, a total of 120 isolates of $V$. parahaemolyticus isolated using IMB were subjected to PCR with species-specific primers (Table 1). Among 120 isolates of $V$. parahaemolyticus, three (2.5\%) and $26(21.7 \%)$ isolates of $V$. parahaemolyticus isolated without and with IMB were positive for the tox R gene as judged by amplification of a $368 \mathrm{bp}$ fragment 253 (Fig. 2 and File S2).

254

255

256

257

258

259

260

261

262 263

\section{Detection of virulence gene markers}

Among the overall tox R gene-positive $V$. parahaemolyticus, 24 (20\%) amplified the $251 \mathrm{bp} t d h$ fragment and the highest number of tdh positive isolates was detected from HMF (Fig. 3 and File $\mathrm{S} 3)$. As presented in Table 3, 21 (17.5\%) of the $t d h$ gene-positive isolates of $V$. parahaemolyticus were isolated with IMB enrichment, and only three (2.5\%) of the $t d h$ gene-positive isolates of $V$. parahaemolyticus were isolated without IMB enrichment. None of the $V$. parahaemolyticus isolates tested positive for the trh gene (Table 3). 
264

265

266

267

268

269

270

271

272

273

274

275

276

277

278

279

280

281

282

283

284

285

286

287

288

289

290

291

\section{Molecular typing}

Among 29 isolates of toxR gene-positive $V$. parahaemolyticus, 24 isolates were genotyped using ERIC-PCR DNA fingerprinting analysis and generated high genomic diversity among $V$.

parahaemolyticus isolates (File S4). The ERIC primer sets produced four to ten fingerprint bands and ranged between 100 to $1200 \mathrm{bp}$ (Fig. 4). Of the 24 genotyped isolates of $V$.

parahaemolyticus, 18 isolates were grouped and identified into four ERIC identical clonal group patterns (Cluster 1, 2, 3, and 4), while a similarity cutoff value of 100\% was applied and six isolates have shown a single cluster (SC) (Table 4 and Fig. 5). Among the four clusters, cluster-2 was comprised of the highest number of $V$. parahaemolyticus isolates with identical clonal origin isolated from AZB, HMF, and KBC corniche between March and April 2018 (Fig. 5).

\section{Discussion}

In this study, potentially toxigenic $V$. parahaemolyticus was isolated from all samples locations, except seawater samples were collected from Alkhubar corniche (KBC). The occurrence of $V$. parahaemolyticus is usually associated with temperature, especially high temperate climate ( $D i$ et al., 2017). In this study, the highest reported temperature during sampling events was $31^{\circ} \mathrm{C}$ and recorded in Half-Moon beach (HMF) during month of April (Table 2). The minimum and maximum $\mathrm{pH}$ values for the growth of $V$. parahaemolyticus in the environment were reported to be 4.8 and 11, respectively (Food and Drug Administration, 2020). The reported $\mathrm{pH}$ in this study are within the optimum range of pH, between 5 and 8.6 (Whitaker et al., 2010; Mudoh et al., 2014). Effectual methods for isolation and identification of $V$. parahaemolyticus from clinical, food, and environmental samples are required to speed identification and minimize the risk of infection (Canizalez-Roman et al., 2011). Our study was able to confirm the isolation of $V$. parahaemolyticus in all examined seawater samples from all locations along the coast while using IMB in the secondary enrichment process (Table 2). To achieve these results, two different 
292 enrichment in APW broth without and with IMB were spread on CaV and TCBS agar for 293 isolation of $V$. parahaemolyticus. In this study, we found the use of IMB in secondary

294 enrichment increased the number of positive samples for $V$. parahaemolyticus while using both 295 selective media (Table 2). However, the number of positive samples detected with the use of 296 IMB in secondary enrichment on TCBS agar and CaV medium was 38 (19.8\%) and 44 (22.9\%), 297 respectively (Table 2). The number positive for $V$. parahaemolyticus without using IMB in 298 secondary enrichment was low in TCBS agar, and $\mathrm{CaV}$ medium was $3(1.6 \%)$ and $5(2.6 \%)$, 299 respectively (Table 2).

300 Consequently, our study used PCR amplification targeted to the toxR gene, by which the 301 identity of $3(2.5 \%)$ and $21(21.7 \%)$ isolates of $V$. parahaemolyticus isolated without and with 302 IMB on TCBS agar and CHROMagar Vibrio was confirmed to the species level, respectively 303 (Table 3). Therefore, our study found that the coupling of IMB in secondary enrichment of 304 environmental samples with toxR PCR assay is a reliable method for the detection of $V$. 305 parahaemolyticus (Kim et al., 1999). Indicators of the potential pathogenicity of $V$. 306 parahaemolyticus is the presence of $t d h$ and trh genes. Almost all clinically isolated strains of $V$. 307 parahaemolyticus possess hemolytic activity attributed to these two genes (Ceccarelli et al., 308 2013). The effect of TDH on intestinal and epithelial cells is crucial for the biological activities, 309 like diarrhea, during V. parahaemolyticus infection ( Shimohata et al., 2010). Also, trh works in 310 an analogous pattern to TDH (Raghunath, 2014). To the best of our knowledge, this study 311 represents the first report of the detection of $t d h$-positive $V$. parahaemolyticus strains from the 312 coastal environment in the Eastern Province of Saudi Arabia.

313 The highest percentage of $t d h$ positivity was $17.5 \%$ from the total isolates detected among $V$.

314 parahemolyticus isolated with IMB enrichment, while the lowest percentage of $t d h$ positive 315 isolates was (2.5\%) detected in V. parahaemolyticus isolated without IMB enrichment (Table 3).

316 From our previous studies were conducted to investigate the presence of toxigenic $V$.

317 parahaemolyticus in costal environment of the Eastern Province of Saudi Arabia, revealed none 318 or less than $1 \%$ detection rate of isolates positive for virulence gene markers (Elhadi et al., 2018; 
319 Ghenem et al., 2018). The detection of TDH positive strains of $V$. parahaemolyticus in the costal

320 environment of the Eastern Province of Saudi Arabia is a pressing concern that has several

321 impacts and requires instant attention. First, the fact that these strains are potentially toxigenic

322 should prompt the healthcare facilities to monitor all bacterial gastroenteritis in clinical samples

323 for the presence of $V$. parahaemolyticus (Jun et al., 2012). Second, incidences where pathogenic

324 . parahaemolyticus was held responsible for contaminating seafood produce and not only

325 causing outbreaks of the infection, but also costing the seafood industry enormous economic

326 losses have been documented (Fuenzalida et al., 2006; Thongiun et al., 2006; Johnson et al.,

327 2010). Thus, the results of this study emphasize the continuous monitoring of seafood products'

328 safety. The ERIC-PCR clusters indicate that the isolates could have originated from the same

329 clonal lineage of $V$. parahaemolyticus. These results agreed with our previous study (Elhadi et

330 al., 2018) and are consistent with Marshall et al (1999), who reported that ERIC-PCR was a

331 useful method for evaluating genetic and epidemiological relationships among $V$.

332 parahaemolyticus. The results obtained in this study are very significant for public health in this

333 coastal region and should prompt us to pay attention to the role of these tdh positive $V$.

334 parahaemolyticus in local foodborne diseases. Furthermore, the results should also underline the

335 need for adequate consumer protection against toxigenic $V$. parahaemolyticus in Eastern

336 Province of Saudi Arabia. In particular, setup of a more elaborate protocol is required while

337 dealing with environmental isolates and seafood consumer education regarding proper cooking is

338 considered important. The isolation of toxigenic $V$. parahaemolyticus in coastal water and

339 seafood samples has been well documented in the USA, Japan, Southeast Asia, and many

340 European countries (Hara-Kudo et al., 2003; Robert-Pillot et al., 2004; Di Pinto et al., 2008;

341 Roque et al., 2009; Johnson et al., 2012; Jun et al., 2012). A future study on the prevalence of 
342 toxigenic $V$. parahaemolyticus in seafood will be necessary to evaluate public health significance

343 of these strains in the coastal environment of the Eastern Province of Saudi Arabia.

\section{Conclusions}

345

346

347

348

349

350

351

352

353

354

355

356

357

358

359

360

361

362

363

364

365

366

367

368

369

370

371

372

373

374

375

376

The study concluded that, both TCBS and CHROMagar Vibrio are suitable selective media for isolation of $V$. parahaemolyticus if IMBs are used in the enrichment process of environmental water samples. Therefore, the use of IMB will separate $V$. parahaemolyticus from Vibrio and other non-Vibrio species in environmental samples and improve the isolation level of V. parahaemolyticus. This study also concludes that CHROMagar Vibrio has no advantage over TCBS agar if the enriched sample is treated with IMBs coated with specific polyvalent $\mathrm{K}$ antisera antibodies for immuno-concentration of $V$. parahaemolyticus. The isolation of tdh positive $V$. parahaemolyticus in this study identifies a public health risk and indicates there is a possibility of the spreading of this gene in the marine environment.

\section{Acknowledgements}

The authors would like to thank Emeritus Professor Mitsuaki Nishibuchi of the Center of Southeast Asian Studies, Kyoto University for useful information and support.

\section{References}

Abanto M, Gavilan RG, Baker-Austin C, Gonzalez-Escalona N, Martinez-Urtaza J. 2020. Global expansion of Pacific Northwest Vibrio parahaemolyticus sequence type 36. Emerging Infectious Diseases 26(2):323 DOI 10.3201/eid2602.190362.

Alipour M, Issazadeh K, Soleimani J. 2014. Isolation and identification of Vibrio parahaemolyticus from seawater and sediment samples in the southern coast of the Caspian Sea. Comparative Clinical Pathology 23(1):129-133 DOI 10.1007/s00580-0121583-6.

Baker-Austin C, Trinanes J, Gonzalez-Escalona N, Martinez-Urtaza J. 2017. Non-cholera vibrios: the microbial barometer of climate change. Trends in Microbiology 25(1):76-84 DOI 10.1016/j.tim.2016.09.008. 
377

378

379

380

381

382

383

384

385

386

387

388

389

390

391

392

393

394

395

396

397

398

399

400

401

402

403

404

405

406

407

408

409

410

411

412

413

414

415

416

417

Blackwell KD, Oliver JD. 2008. The ecology of Vibrio vulnificus, Vibrio cholerae, and Vibrio parahaemolyticus in North Carolina estuaries. The Journal of Microbiology 46(2):146153 DOI 10.1007/s12275-007-0216-2.

Böer SI, Heinemeyer EA, Luden K, Erler R, Gerdts G, Janssen F, Brennholt N. 2013. Temporal and spatial distribution patterns of potentially pathogenic Vibrio spp. at recreational beaches of the German North Sea. Microbial Ecology 65(4):1052-1067 DOI 10.1007/s00248-013-0221-4.

Broberg CA, Calder TJ, Orth K. 2011. Vibrio parahaemolyticus cell biology and pathogenicity determinants. Microbes and Infection 13(12-13):992-1001. DOI 10.1016/j.micinf.2011.06.013.

Canizalez-Roman A, Flores-Villaseñor H, Zazueta-Beltran J, Muro-Amador S, LeónSicairos N. 2011. Comparative evaluation of a chromogenic agar medium-PCR protocol with a conventional method for isolation of Vibrio parahaemolyticus strains from environmental and clinical samples. Canadian journal of Microbiology 57(2):136-142 DOI 10.1139/w10-108.

Ceccarelli D, Hasan NA, Huq A, Colwell RR. 2013. Distribution and dynamics of epidemic and pandemic Vibrio parahaemolyticus virulence factors. Frontiers in Cellular and Infection Microbiology 3:97 DOI 10.3389/fcimb.2013.00097.

DePaola A, Kaysner, CA. 2004. Vibrio. Bacteriological analytical manual online. Washington, DC: US Food and Drug Administration.

DePaola A, Nordstrom JL, Bowers JC, Wells JG, Cook DW. 2003. Seasonal abundance of total and pathogenic Vibrio parahaemolyticus in Alabama oysters. Applied and Environmental Microbiology 69(3):1521-1526. DOI 10.1128/aem.69.3.1521-1526.2003.

Di DY, Lee A, Jang J, Han D, Hur HG. 2017. Season-specific occurrence of potentially pathogenic Vibrio spp. on the southern coast of South Korea. Applied and Environmental Microbiology 83(3):e02680-16 DOI 10.1128/AEM.02680-16.

Di Pinto A, Terio V, Novello L, Tantillo G. 2011. Comparison between thiosulphate-citrate-bile salt sucrose (TCBS) agar and CHROMagar Vibrio for isolating Vibrio parahaemolyticus. Food Control 22(1):124-127 DOI:10.1016/j.foodcont.2010.06.013.

Elhadi N. 2013. Occurrence of potentially human pathogenic Vibrio species in the coastal water of the Eastern Province of Saudi Arabia. Research Journal of Microbiology 8(1): 1 . 
418

419

420

421

422

423

424

425

426

427

428

429

430

431

432

433

434

435

436

437

438

439

440

441

442

443

444

445

446

447

448

449

450

451

452

453

454

455

456

457

458

Elhadi N, Nishibuchi M. 2018. Characterization of Vibrio parahaemolyticus isolated from coastal water in Eastern Province of Saudi Arabia. Malaysian Journal of Microbiology 14(1):1-9 DOI 10.21161/mjm.96316.

Elhadi N. 2018. Clonal relationship among the Vibrio parahaemolyticus isolates from coastal water in Saudi Arabia. The Egyptian Journal of Aquatic Research 44(2):131-137 DOI 10.1016/j.ejar.2018.04.002.

Fabbro C, Cataletto B, Del Negro P. 2010. Detection of pathogenic Vibrio parahaemolyticus through biochemical and molecular-based methodologies in coastal waters of the Gulf of Trieste (North Adriatic Sea). FEMS Microbiology Letters 307(2):158-164 DOI 10.1111/j.1574-6968.2010.01969.x.

FAO and WHO. 2020. Risk assessment tools for Vibrio parahaemolyticus and Vibrio vulnificus associated with seafood. Microbiological Risk Assessment Series No. 20. Rome.

Fuenzalida L, Hernández C, Toro J, Rioseco ML, Romero J, Espejo RT. 2006. Vibrio parahaemolyticus in shellfish and clinical samples during two large epidemics of diarrhoea in southern Chile. Environmental Microbiology 8(4):675-683.

DOI 10.1111/j.1462-2920.2005.00946.x.

Ghenem L, Elhadi N. 2018. Isolation, molecular characterization, and antibiotic resistance patterns of Vibrio parahaemolyticus isolated from coastal water in the Eastern Province of Saudi Arabia. Journal of Water and Health 16(1):57-69 DOI 10.2166/wh.2017.361.

Hara-Kudo Y, Sugiyama K, Nishina T, Saitoh A, Nakagawa H, Ichihara T, Konuma H, Hasegawa J, Kumagai S. 2001. Detection of TDH-producing Vibrio parahaemolyticus O3: K6 from naturally contaminated shellfish using an immunomagnetic separation method and chromogenic agar medium. Kansenshogaku zasshi. The Journal of the Japanese Association for Infectious Diseases 75(11):955-60. DOI 10.11150/kansenshogakuzasshi1970.75.955.

Hara-Kudo Y, Sugiyama K, Nishibuchi M, Chowdhury A, Yatsuyanagi J, Ohtomo Y, Saito A, Nagano H, Nishina T, Nakagawa H, Konuma H. 2003. Prevalence of pandemic thermostable direct hemolysin-producing Vibrio parahaemolyticus O3: K6 in seafood and the coastal environment in Japan. Applied and Environmental Microbiology 69(7):3883-91. DOI 10.1128/AEM.69.7.3883-3891.2003.

Peer) reviewing PDF | (2021:05:61286:1:0:NEW 20 Sep 2021) 
459

460

461

462

463

464

465

466

467

468

469

470

471

472

473

474

475

476

477

478

479

480

481

482

483

484

485

486

487

488

489

490

491

492

493

494

495

496

497

498

499

Heras J, Domínguez C, Mata E, Pascual V, Lozano C, Torres C, Zarazaga M. 2015. GelJ-a tool for analyzing DNA fingerprint gel images. BMC Bioinformatics 16(1):1-8. DOI 10.1186/s12859-015-0703-0 (2015).

Hlady WG, Klontz KC. 1996. The epidemiology of Vibrio infections in Florida, 1981-1993. Journal of Infectious Diseases 173(5):1176-83 DOI 10.1093/infdis/173.5.1176.

International Commission on Microbiological Specifications for Foods (ICMSF). 1996. Microorganisms in Foods 5-Microbiological specifications of food pathogens. London, Blackie Academic and Professional.

Jacxsens L, Kussaga J, Luning PA, Van der Spiegel M, Devlieghere F, Uyttendaele M. 2009. A microbial assessment scheme to measure microbial performance of food safety management systems. International Journal of Food Microbiology 134(1-2):113-125 DOI 10.1016/j.ijfoodmicro.2009.02.018.

Jia L, Lin C, Gao Z, Qu M, Yang J, Sun J, Chen H, Wang Q. 2016. Prevalence and factors associated with different pathogens of acute diarrhea in adults in Beijing, China. The Journal of Infection in Developing Countries 10(11):1200-1207 DOI 10.3855/jidc.6831.

Johnson CN, Bowers JC, Griffitt KJ, Molina V, Clostio RW, Pei S, Laws E, Paranjpye RN, Strom MS, Chen A, Hasan NA. 2012. Ecology of Vibrio parahaemolyticus and Vibrio vulnificus in the coastal and estuarine waters of Louisiana, Maryland, Mississippi, and Washington (United States). Applied and Environmental Microbiology 78(20):7249-7257 DOI 10.1128/AEM.01296-12.

Johnson CN, Flowers AR, Noriea NF, Zimmerman AM, Bowers JC, DePaola A, Grimes DJ. 2010. Relationships between environmental factors and pathogenic vibrios in the northern Gulf of Mexico. Applied and Environmental Microbiology 76(21):7076-7084 DOI 10.1128/AEM.00697-10.

Julie D, Solen L, Antoine V, Jaufrey C, Annick D, Dominique HH. 2010. Ecology of pathogenic and non-pathogenic Vibrio parahaemolyticus on the French Atlantic coast. Effects of temperature, salinity, turbidity and chlorophyll a. Environmental Microbiology 12(4):929-37 DOI 10. 111/j.1462-2920.2009.02136.x.

Jun JW, Kim JH, Choresca Jr CH, Shin SP, Han JE, Han SY, Chai JY, Park SC. 2012. Isolation, molecular characterization, and antibiotic susceptibility of Vibrio parahaemolyticus in Korean seafood. Foodborne Pathogens and Disease 9(3):224-31 DOI 10.1089/fpd.2011.1018.

Peer] reviewing PDF | (2021:05:61286:1:0:NEW 20 Sep 2021) 
500

501

502

503

504

505

506

507

508

509

510

511

512

513

514

515

516

517

518

519

520

521

522

523

524

525

526

527

528

529

530

531

532

533

534

535

536

537

538

539

Kalburge SS, Whitaker WB, Boyd EF. 2014. High-salt preadaptation of Vibrio parahaemolyticus enhances survival in response to lethal environmental stresses. Journal of Food Protection 77(2):246-53 DOI 10.4315/0362-028X.JFP-13-241.

Kaneko T, Colwell RR. 1973. Ecology of Vibrio parahaemolyticus in Chesapeake bay. Journal of Bacteriology 113(1):24-32 DOI 10.1128/JB.113.1.24-32.1973.

Kim YB, Okuda JU, Matsumoto C, Takahashi N, Hashimoto S, Nishibuchi M. 1999. Identification of Vibrio parahaemolyticus strains at the species level by PCR targeted to the toxR gene. Journal of Clinical Microbiology 37(4):1173-1177 DOI 10.1128/JCM.37.4.1173-1177.1999.

Larsen AM, Rikard FS, Walton WC, Arias CR. 2015. Temperature effect on high salinity depuration of Vibrio vulnificus and $V$. parahaemolyticus from the Eastern oyster (Crassostrea virginica). International Journal of Food Microbiology 192:66-71 DOI 10.1016/j.ijfoodmicro_.2014.09.025.

Letchumanan V, Chan KG, Lee LH. 2014. Vibrio parahaemolyticus: a review on the pathogenesis, prevalence, and advance molecular identification techniques. Frontiers in Microbiology 5:705 DOI 10.3389/fmicb.2014.00705.

Li J, Xue F, Yang Z, Zhang X, Zeng D, Chao G, Jiang Y, Li B. 2016. Vibrio parahaemolyticus strains of pandemic serotypes identified from clinical and environmental samples from Jiangsu, China. Frontiers in Microbiology 7:787 DOI 10.3389/fmicb.2016.00787.

Liu J, Bai L, Li W, Han H, Fu P, Ma X, Bi Z, Yang X, Zhang X, Zhen S, Deng X. 2018. Trends of foodborne diseases in China: lessons from laboratory-based surveillance since 2011. Frontiers of Medicine 12(1):48-57 DOI 10.1007/s11684-017-0608-6.

Marder EP, Griffin PM, Cieslak PR, Dunn J, Hurd S, Jervis R, Lathrop S, Muse A, Ryan P, Smith K, Tobin-D'Angelo M. 2018. Preliminary incidence and trends of infections with pathogens transmitted commonly through food-foodborne diseases active surveillance network, 10 US Sites, 2006-2017. Morbidity and Mortality Weekly Report 67(11):324 DOI 10.1111/ajt. 15412.

Marshall S, Clark CG, Wang G, Mulvey M, Kelly MT, Johnson WM. 1999. Comparison of Molecular Methods for Typing Vibrio parahaemolyticus. Journal of Clinical Microbiology. 37(8):2473-2478 DOI 10.1128/JCM.37.8.2473-2478.1999. 
540 Martinez-Urtaza J, Bowers JC, Trinanes J, DePaola A. 2010. Climate anomalies and the

541

542

543

544

545

546

547

548

549

550

551

552

553

554

555

556

557

558

559

560

561

562

563

564

565

566

567

568

569

570

571

572

573

574

575

576

577

578

579

580 increasing risk of Vibrio parahaemolyticus and Vibrio vulnificus illnesses. Food Research International 43(7):1780-90 DOI 10.1016/ j.foodres.2010.04.001.

Martinez-Urtaza J, Powell A, Jansa J, Rey JL, Montero OP, Campello MG, López MJ, Pousa A, Valles MJ, Trinanes J, Hervio-Heath D. 2016. Epidemiological investigation of a foodborne outbreak in Spain associated with US West Coast genotypes of Vibrio parahaemolyticus. Springerplus 5(1):1-8 DOI 10.1186/s40064-016-1728-1.

McLaughlin JB, DePaola A, Bopp CA, Martinek KA, Napolilli NP, Allison CG, Murray SL, Thompson EC, Bird MM, Middaugh JP. 2005. Outbreak of Vibrio parahaemolyticus gastroenteritis associated with Alaskan oysters. New England Journal of Medicine 353(14):1463-70 DOI 10.1056/NEJMoa051594.

Mudoh M, Parveen S, Schwarz J, Rippen T, Chaudhuri A. 2014. The effects of storage temperature on the growth of Vibrio parahaemolyticus and organoleptic properties in oysters. Frontiers in Public Health 2:45 DOI 10.3389/fpubh.2014.00045.

Nair GB, Ramamurthy T, Bhattacharya SK, Dutta B, Takeda Y, Sack DA. 2007. Global dissemination of Vibrio parahaemolyticus serotype O3: K6 and its serovariants. Clinical microbiology reviews. 20(1):39-48 DOI 10.1128/CMR.00025-06.

Newton AE, Garrett N, Stroika SG, Halpin JL, Turnsek M, Mody RK. 2014. Notes from the field: increase in Vibrio parahaemolyticus infections associated with consumption of Atlantic Coast shellfish—2013. MMWR Morb Mortal Wkly Rep 63:335-336. PMCID PMC5779391.

Parveen S, Hettiarachchi KA, Bowers JC, Jones JL, Tamplin ML, McKay R, Beatty W, Brohawn K, DaSilva LV, DePaola A. 2008. Seasonal distribution of total and pathogenic Vibrio parahaemolyticus in Chesapeake Bay oysters and waters. International Journal of Food Microbiology 128(2):354-61 DOI 10.1016/j.ijfoodmicro.2008.09.019.

Raghunath P. 2015. Roles of thermostable direct hemolysin (TDH) and TDH-related hemolysin (TRH) in Vibrio parahaemolyticus. Frontiers in microbiology 22;5:805. DOI 10.3389/fmicb. 014.00805.

Robert-Pillot A, Guénolé A, Lesne J, Delesmont R, Fournier JM, Quilici ML. 2004. Occurrence of the tdh and trh genes in Vibrio parahaemolyticus isolates from waters and raw shellfish collected in two French coastal areas and from seafood imported into France. International Journal of Food Microbiology 91(3):319-25. DOI 10.1016/j.jijoodmicro.2003.07.006.

Peer] reviewing PDF | (2021:05:61286:1:0:NEW 20 Sep 2021) 
581

582

583

584

585

586

587

588

589

590

591

592

593

594

595

596

597

598

599

600

601

602

603

604

605

606

607

608

609

610

611

612

613

614

615

616

617

618

619

620

621

Roque A, Lopez-Joven C, Lacuesta B, Elandaloussi L, Wagley S, Furones MD, RuizZarzuela I, de Blas I, Rangdale R, Gomez-Gil B. 2009. Detection and identification of tdh-and trh-positive Vibrio parahaemolyticus strains from four species of cultured bivalve molluscs on the Spanish Mediterranean Coast. Applied and Environmental Microbiology 75(23):7574-7577. DOI 10.1128/AEM.00772-09.

Saito S, Iwade Y, Tokuoka E, Nishio T, Otomo Y, Araki E, Konuma H, Nakagawa H, Tanaka H, Sugiyama K, Hasegawa A.2015. Epidemiological Evidence of Lesser Role of Thermostable Direct Hemolysin (TDH)-Related Hemolysin (TRH) Than TDH on Vibrio parahaemolyticus Pathogenicity. Foodborne Pathogens and Disease 12(2):131138._doi: 10.1089/fpd.2014.1810.

Scallan E, Hoekstra RM, Angulo FJ, Tauxe RV, Widdowson MA, Roy SL, Jones JL, Griffin PM. 2011. Foodborne illness acquired in the United States-major pathogens. Emerging Infectious Diseases 17(1):7 DOI 10.3201/eid1701.p11101.

Shimohata T, Takahashi A. 2010. Diarrhea induced by infection of Vibrio parahaemolyticus. The Journal of Medical Investigation 57(3, 4):179-182 DOI 10.2152/jmi.57.179.

Su YC, Liu C. 2007. Vibrio parahaemolyticus: a concern of seafood safety. Food microbiology. 24(6):549-558. DOI10.1016/j.fm.2007.01.005.

Tada J, Ohashi T, Nishimura N, Shirasaki Y, Ozaki H, Fukushima S, Takano J, Nishibuchi M, Takeda Y. 1992. Detection of the thermostable direct hemolysin gene (tdh) and the thermostable direct hemolysin-related hemolysin gene (trh) of Vibrio parahaemolyticus by polymerase chain reaction. Molecular and Cellular Probes 6(6):477-87. doi: 10.1016/0890-8508(92)90044-X.

Tanaka N, Iwade Y, Yamazaki W, Gondaira F, Vuddhakul V, Nakaguchi Y, Nishibuchi M. 2014. Most-Probable-Number Loop-Mediated Isothermal Amplification-Based Procedure Enhanced with K Antigen-Specific Immunomagnetic Separation for Quantifying tdh+ Vibrio parahaemolyticus in Molluscan Shellfish. Journal of Food Protection 77(7):107885 DOI 10.4315/0362-028X.JFP-13-536.

Thongjun J, Mittraparp-Arthorn P, Yingkajorn M, Kongreung J, Nishibuchi M, Vuddhakul V. 2013. The trend of Vibrio parahaemolyticus infections in Southern Thailand from 2006 to 2010. Tropical Medicine and Health 41(4):151-6 DOI 10.2149/tmh.2013-06.

Peer) reviewing PDF | (2021:05:61286:1:0:NEW 20 Sep 2021) 
622 Food and Drug Administration. 2020. Fishery products hazards and controls guidance, 2020.

623

624

625

626

627

628

629

630

631

632

633

634

635

636

637

638

639

640

641

642

643 Available at https://www.fda.gov/food/seafood-guidance-documents-regulatoryinformation/fish-and-fishery-products-hazards-and-controls (Accessed on 14 July 2020).

Versalovic J, Koeuth T, Lupski R. 1991. Distribution of repetitive DNA sequences in eubacteria and application to finerpriting of bacterial genomes. Nucleic Acids Research 19(24):6823-6831 DOI 10.1093/nar/19.24.6823.

Whitaker WB, Parent MA, Naughton LM, Richards GP, Blumerman SL, Boyd EF. 2010. Modulation of responses of Vibrio parahaemolyticus $\mathrm{O} 3$ : $\mathrm{K} 6$ to $\mathrm{pH}$ and temperature stresses by growth at different salt concentrations. Applied and Environmental Microbiology 76(14):4720-4729._DOI 10.1128/AEM.00474-10.

Yonekita T, Morishita N, Arakawa E, Matsumoto T. 2020. Development of a monoclonal antibody for specific detection of Vibrio parahaemolyticus and analysis of its antigen. Journal of Microbiological Methods 173:105919 DOI 10.1016/j.mimet.2020.105919.

Yoon KS, Min KJ, Jung YJ, Kwon KY, Lee JK, Oh SW. 2008. A model of the effect of temperature on the growth of pathogenic and nonpathogenic Vibrio parahaemolyticus isolated from oysters in Korea. Food Microbiology 25(5):635-41 DOI

10.1016/j.fm.2008.04.007. 
Table $\mathbf{1}$ (on next page)

Primer used in this study 
$1 \quad$ Table 1 Primer used in this study.

\begin{tabular}{lllll}
\hline $\begin{array}{l}\text { Primer } \\
\text { specificity }\end{array}$ & Primer sequence & $\begin{array}{l}\text { Amplicon } \\
\text { size (bp) }\end{array}$ & $\begin{array}{l}\text { Annealing } \\
\text { temperature }\left(^{\mathbf{0} C)}\right.\end{array}$ & Reference \\
\hline $\boldsymbol{t} \boldsymbol{x} \mathbf{R}$ & $\begin{array}{l}\text { Forward: 5'-GTCTTCTGACGCAATCGTTG-3' } \\
\text { Reverse: 5'-ATACGAGTGGTTGCTGTCATG-3' }\end{array}$ & 368 & 63 & (Kim et al., 1999) \\
$\boldsymbol{t} \boldsymbol{d} \boldsymbol{h}$ & $\begin{array}{l}\text { Forward: 5'-CCACTACCACTCTCATATGC-3' } \\
\text { Reverse: 5'-GGTACTAAATGGCTGACATC-3' }\end{array}$ & 251 & 55 & (Tada et al., 1992) \\
$\boldsymbol{t} \boldsymbol{h} \boldsymbol{l}$ & $\begin{array}{l}\text { Forward: 5'-GGCTCAAAATGGTTAAGCG-3' } \\
\text { Reverse: 5'-CATTTCCGCTCTCATATGC-3' }\end{array}$ & 250 & 58 & (Tada et al., 1992) \\
\hline
\end{tabular}

2

3

4 


\section{Table 2 (on next page)}

Distribution of $V$. parahaemolyticus isolated with and without IMB from different locations 
Table 2 Distribution of $V$. parahaemolyticus isolated with and without IMB from different locations.

\begin{tabular}{|c|c|c|c|c|c|c|c|c|}
\hline \multirow{3}{*}{ Location } & \multirow{3}{*}{ No. of samples } & \multirow{3}{*}{ Date of collection } & \multirow{2}{*}{\multicolumn{2}{|c|}{ Surface seawater }} & \multicolumn{4}{|c|}{ Number of positive samples (\%) } \\
\hline & & & & & Isolated witl & It IMB on & \multicolumn{2}{|c|}{ Isolated with IMB on } \\
\hline & & & Temp $\left({ }^{\circ} \mathrm{C}\right)$ & pH & TCBS agar & $\mathrm{CaV}$ & TCBS agar & $\mathrm{CaV}$ \\
\hline AZB & 40 & 4 March 2018 & 25 & 8.18 & $3(7.5)$ & $5(12.5)$ & $11(27.5)$ & $15(37.5)$ \\
\hline KBC & 39 & 25 March 2018 & 27.5 & 7.35 & 0 & 0 & $6(15.4)$ & $6(15.4)$ \\
\hline KBF & 38 & 8 April 2018 & 28 & 8.18 & 0 & 0 & $2(5.3)$ & $2(5.3)$ \\
\hline HMF & 39 & 22 April 2018 & 31 & 8.22 & 0 & 0 & $17(43.6)$ & $19(48.7)$ \\
\hline DMC & 36 & 5 May 2018 & 28 & 8.46 & 0 & 0 & $2(5.6)$ & $2(5.6)$ \\
\hline TOTAL & 192 & & & & $3(1.6)$ & $5(2.6)$ & $38(19.8)$ & $44(22.9)$ \\
\hline
\end{tabular}

3

4 
Figure 1

Map showing locations of the sampling sites

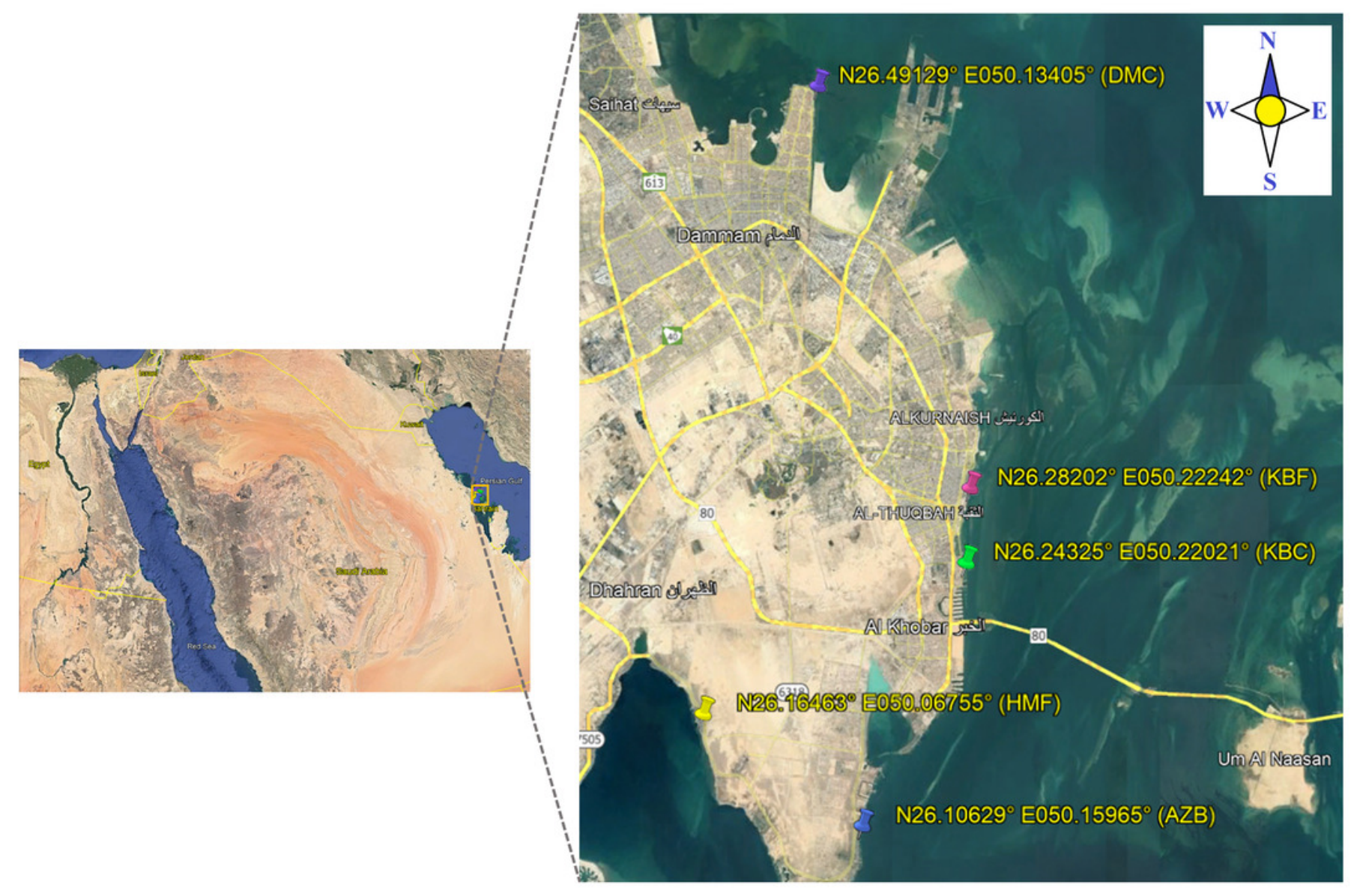

Figure Map showing locations of the sampling sites 
Figure 2

Representative electrophoresis image of PCR amplification of the toxR gene (368 bp fragment). Lane 1, molecular weight marker (100 bp DNA ladder; Promega); 2, V. parahaemolyticus ATCC 17802 (positive control); 3, negative control; 4-18, tested isolates fo 


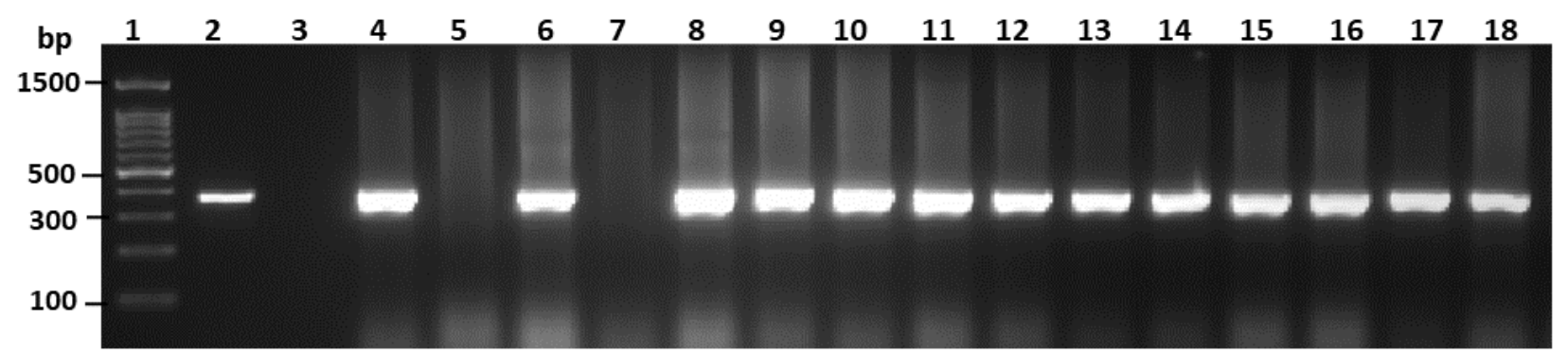

Figure 2 Representative electrophoresis image of PCR amplification of the toxR gene ( $368 \mathrm{bp}$ fragment). Lane 1, molecular weight marker (100 bp DNA ladder; Promega); 2, V. parahaemolyticus ATCC 17802 (positive control); 3, negative control; 4-18, tested isolates for toxR gene. 


\section{Table 3 (on next page)}

Confirmation of $V$. parahaemolyticus isolated with and without IMB treatment targeting species (toxR) and virulence gene (tdh/trh) markers by using PCR 
1

2 Table 3 Confirmation of $V$. parahaemolyticus isolated with and without IMB treatment targeting species (toxR)

3 and virulence gene $(t d h / t r h)$ markers by using PCR.

\begin{tabular}{|c|c|c|c|c|c|c|c|}
\hline \multirow{3}{*}{ Location } & \multirow{3}{*}{$\begin{array}{l}\text { No. of tested } \\
\text { isolates }\end{array}$} & \multicolumn{6}{|c|}{ Number of $V \cdot$ parahaemolyticus isolates } \\
\hline & & \multicolumn{3}{|c|}{ Isolated without IMB and positive for: } & \multicolumn{3}{|c|}{ Isolated with IMB and positive for: } \\
\hline & & tox $\mathrm{R}$ gene & tdh gene & trh gene & tox R gene & $t d h$ gene & trh gene \\
\hline AZB & 45 & 3 & 3 & 0 & 4 & 3 & 0 \\
\hline KBC & 17 & 0 & 0 & 0 & 1 & 1 & 0 \\
\hline KBF & 6 & 0 & 0 & 0 & 0 & 0 & 0 \\
\hline HMF & 48 & 0 & 0 & 0 & 19 & 15 & 0 \\
\hline DMC & 4 & 0 & 0 & 0 & 2 & 2 & 0 \\
\hline Total (\%) & 120 & $3(2.5 \%)$ & $3(2.5 \%)$ & 0 & $26(21.7 \%)$ & $21(17.5 \%)$ & 0 \\
\hline
\end{tabular}

4 
Figure 3

Representative electrophoresis image of PCR amplification of the tdh gene (251 bp fragment). Lane 1, molecular weight marker (100 bp DNA ladder; Promega); 2, V. parahaemolyticus AQ3815 (positive control); 3, negative control; 4-20, positive isolates for $t$ 


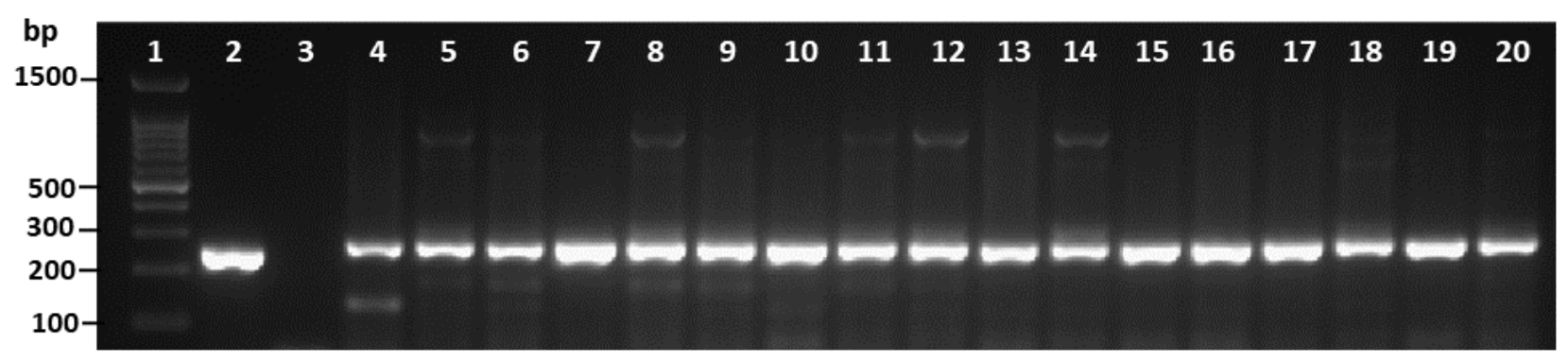

Figure 3 Representative electrophoresis image of PCR amplification of the $t d h$ gene ( $251 \mathrm{bp}$ fragment). Lane 1, molecular weight marker (100 bp DNA ladder; Promega); 2, V. parahaemolyticus AQ3815 (positive control); 3 , negative control; 4-20, positive isolates for $t d h$ gene isolated in this study. 
Figure 4

Amplified DNA fingerprints produced by ERIC-PCR. Lane 1, 100 bp DNA ladder; from lane 2 to 20 representative isolates of $\mathrm{V}$. parahaemolyticus isolated in this study. 


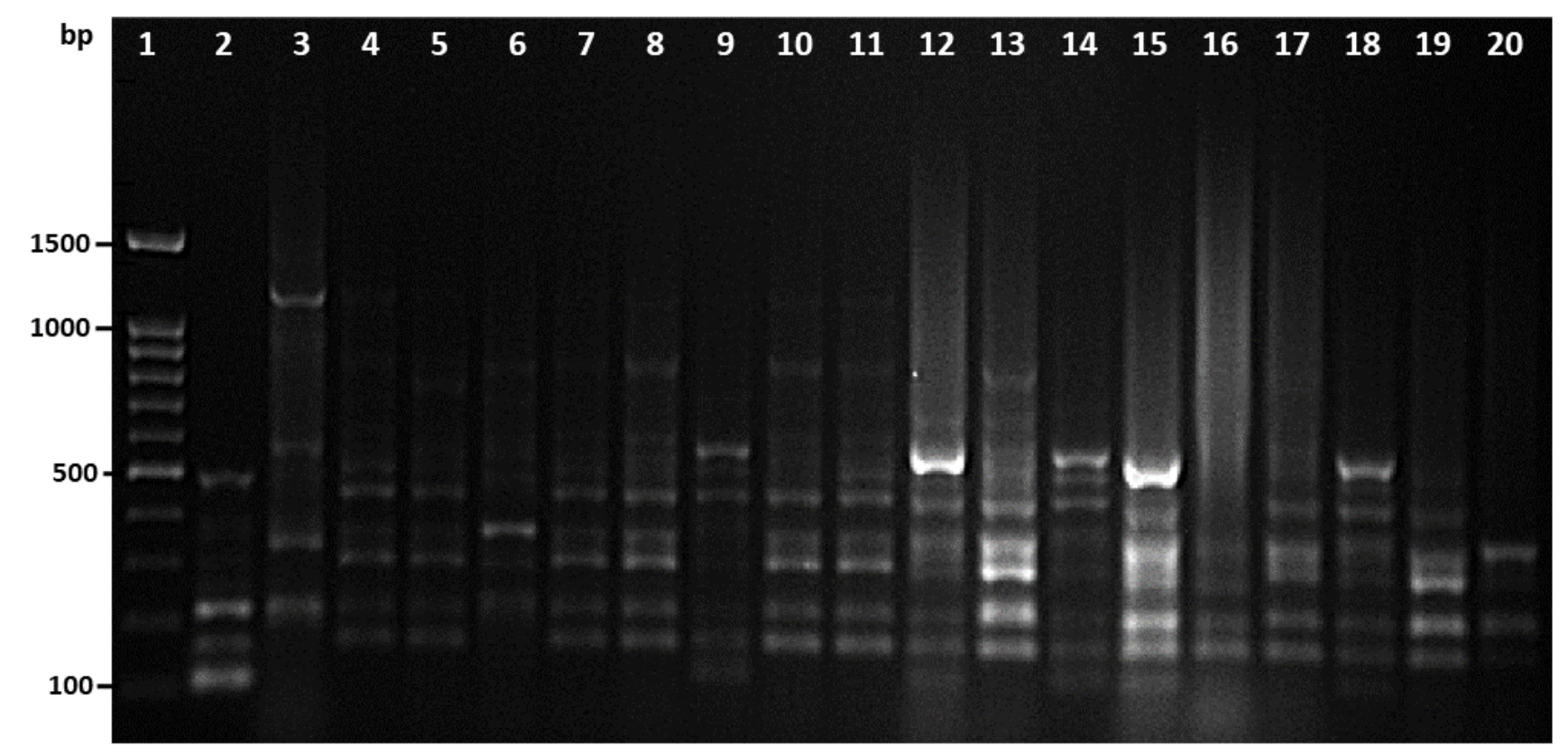

Figure 4 Amplified DNA fingerprints produced by ERIC-PCR. Lane 1, 100 bp DNA ladder; from lane 2 to 20 representative isolates of $V$. parahaemolyticus isolated in this study. 


\section{Table 4 (on next page)}

Molecular characterization of $V$. parahaemolyticus isolated with and without IMB treatment 
1 Table 4 Molecular characterization of $V$. parahaemolyticus isolated with and without IMB treatment.

\begin{tabular}{|c|c|c|c|c|c|c|c|}
\hline \multirow{2}{*}{ No } & \multirow{2}{*}{ Strain code } & \multirow{2}{*}{ Sample location } & \multirow[t]{2}{*}{ Isolation date } & \multirow[b]{2}{*}{ tox $\mathrm{R}$ gene } & \multicolumn{2}{|c|}{ Virulence gene } & \multirow{2}{*}{ ERIC type } \\
\hline & & & & & $t d h$ & trh & \\
\hline 1 & VP-7 & $\mathrm{AZB}$ & 4 March 2018 & + & + & - & ET-4 \\
\hline 2 & VP-31-A & AZB & 4 March 2018 & + & + & - & $\mathrm{ND}^{*}$ \\
\hline 3 & VP-31-B & $\mathrm{AZB}$ & 4 March 2018 & + & - & - & ET-2 \\
\hline 4 & VP-32 & AZB & 4 March 2018 & + & + & - & ET-2 \\
\hline 5 & VP-36 & AZB & 4 March 2018 & + & + & - & $\mathrm{SC}^{\Psi}$ \\
\hline 6 & VP-37 & AZB & 4 March 2018 & + & + & - & ET-2 \\
\hline 7 & VP-49 & $\mathrm{KBC}$ & 25 March 2018 & + & + & - & ET-2 \\
\hline 8 & VP-118 & $\mathrm{HMF}$ & 22 April 2018 & + & + & - & ET-4 \\
\hline 9 & VP-121 & $\mathrm{HMF}$ & 22 April 2018 & + & + & - & ET-2 \\
\hline 10 & VP-123-A & $\mathrm{HMF}$ & 22 April 2018 & + & - & - & ET-2 \\
\hline 11 & VP-123-B & $\mathrm{HMF}$ & 22 April 2018 & + & + & - & ET-4 \\
\hline 12 & VP-123-C & $\mathrm{HMF}$ & 22 April 2018 & + & + & - & ET-2 \\
\hline 13 & VP-125-A & HMF & 22 April 2018 & + & - & - & $\mathrm{SC}$ \\
\hline 14 & VP-125-A & $\mathrm{HMF}$ & 22 April 2018 & + & + & - & ET-4 \\
\hline 15 & VP-126 & HMF & 22 April 2018 & + & + & - & ND \\
\hline 16 & VP-129-A & $\mathrm{HMF}$ & 22 April 2018 & + & + & - & ET-3 \\
\hline 17 & VP-129-B & $\mathrm{HMF}$ & 22 April 2018 & + & - & - & ET-4 \\
\hline 18 & VP-130-A & HMF & 22 April 2018 & + & - & - & ET-3 \\
\hline 19 & VP-130-A-B & $\mathrm{HMF}$ & 22 April 2018 & + & + & - & $\mathrm{SC}$ \\
\hline 20 & VP-132 & $\mathrm{HMF}$ & 22 April 2018 & + & + & - & $\mathrm{SC}$ \\
\hline 21 & VP-133 & $\mathrm{HMF}$ & 22 April 2018 & + & + & - & ND \\
\hline 22 & VP-134 & $\mathrm{HMF}$ & 22 April 2018 & + & + & - & ET-1 \\
\hline 23 & VP-137 & $\mathrm{HMF}$ & 22 April 2018 & + & + & - & ET-1 \\
\hline 24 & VP-145 & $\mathrm{HMF}$ & 22 April 2018 & + & + & - & ET-1 \\
\hline 25 & VP-151 & $\mathrm{HMF}$ & 22 April 2018 & + & + & - & ET-1 \\
\hline 26 & VP-152 & $\mathrm{HMF}$ & 22 April 2018 & + & + & - & $\mathrm{SC}$ \\
\hline 27 & VP-153 & $\mathrm{HMF}$ & 22 April 2018 & + & + & - & ND \\
\hline 28 & VP-165 & $\mathrm{DMC}$ & 5 May 2018 & + & + & - & $\mathrm{SC}$ \\
\hline 29 & VP-166 & DMC & 5 May 2018 & + & + & - & ND \\
\hline
\end{tabular}

2 ND*, not determined; $\mathrm{SC}^{\Psi}$, a single cluster. 
Figure 5

ERIC-PCR dendrogram of toxR and tdh gene-positive strains of V. parahaemolyticus isolated from coastal water in this study. Cluster 1 to 4 denotes identical clonal groups of $\mathrm{V}$. parahaemolyticus strains

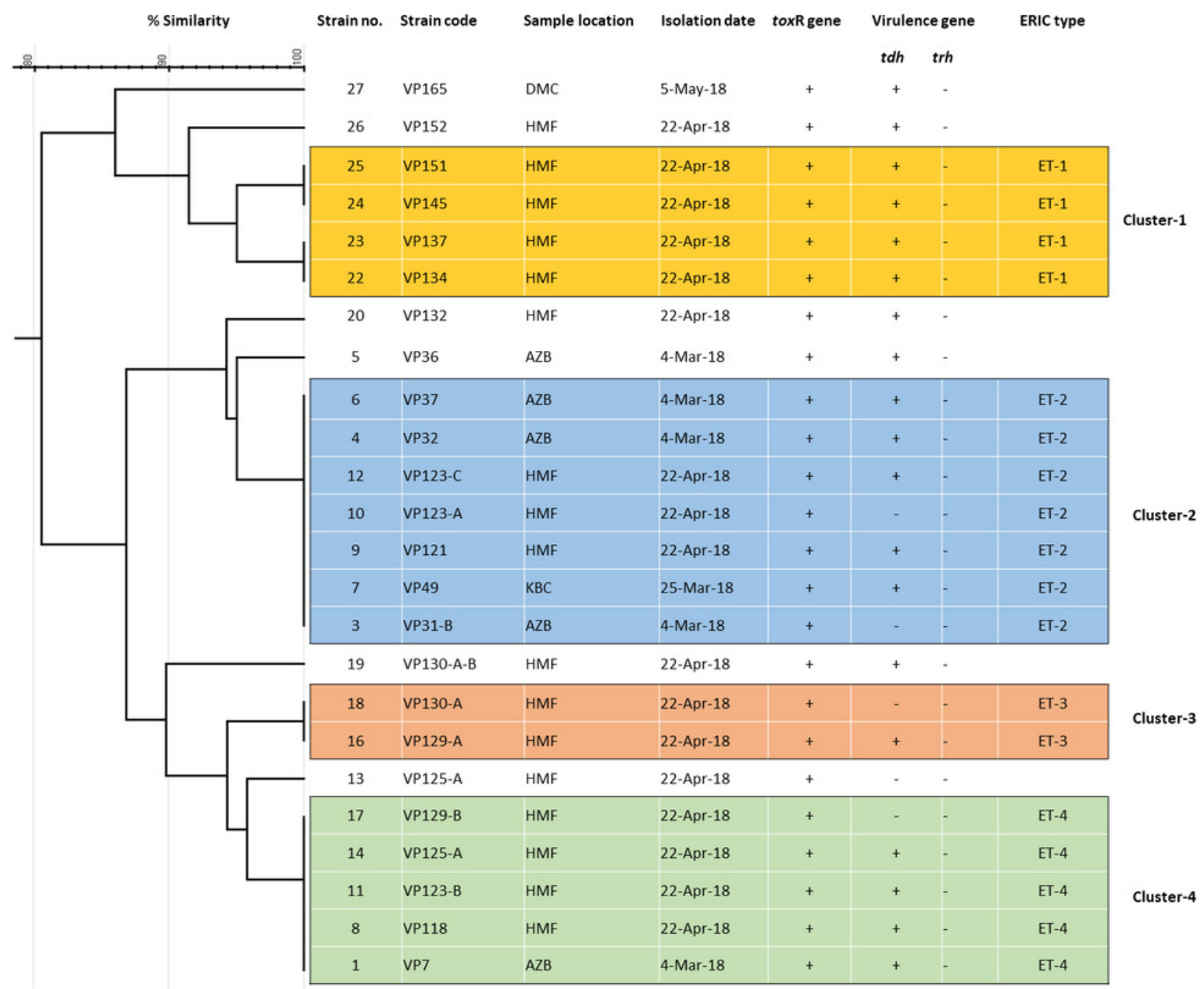

Figure 5 ERIC-PCR dendrogram of toxR and $t d h$ gene-positive strains of $V$. parahaemolyticus isolated from coastal water in this study. Cluster 1 to 4 denotes identical clonal groups of $V$. parahaemolyticus strains 